\title{
MORAL THEORIES, IMPARTIALITY, AND THE STATUS OF NON-RATIONAL, SENTIENT BEINGS
}

\author{
Carlo Fllice \\ State University of New York \\ Geneseo
}

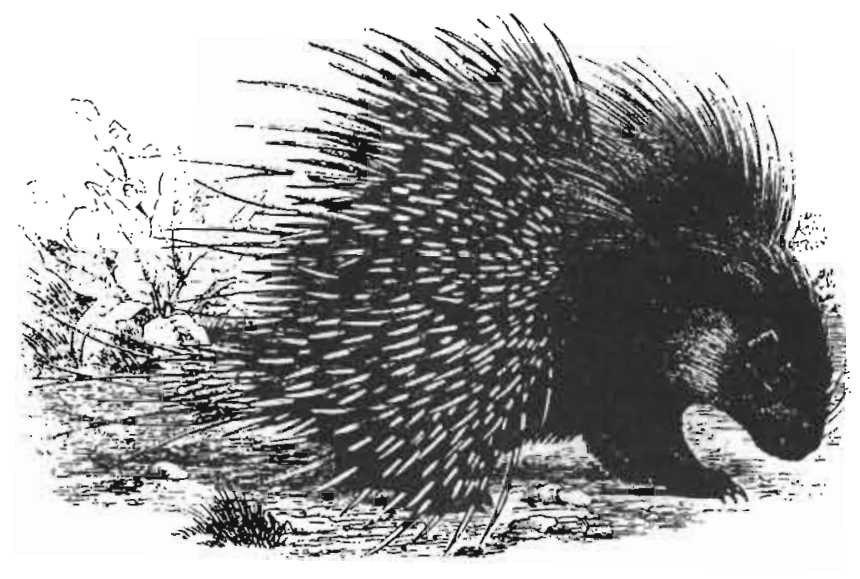

Biased philosophical theorizing about moral matters is doubly reproachable. After all, both genuine philosophy and genuine morality aim at unprejudiced viewpoints. Surely their union should produce no less. This, however, has hardly been the case; witness moral philosophy's historical accommodation with, if not outright support of, wrongful practices like slavery, the subjection of women, and the slaughter of animals for human wants. In this paper I will explore the underlying value assumptions which have contributed to this historical record. The two value assumptions which have been the most pervasive and influential in traditional moral theory are rationalty and pleasure. Exclusive reliance on either of these two basic values leads, I will argue, to an inadequate moral theory. Rationality-based moral theories tend to inflate unjustiflably the value of (some) humans at the expense of the value of other sentient beings. Pleasure-based moral theories, on the other hand, tend to be impartial, but not complete. A complete

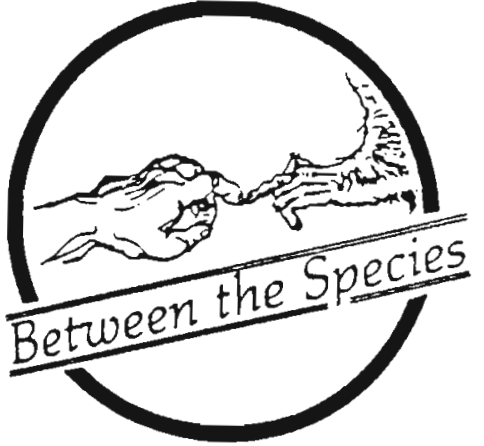

and impartial moral theory, I will argue, will acknowledge pleasure (or sentience) as the primary intrinsic value; but will also acknowledge a formal and independently based value-aspect of our world (of which value-aspect rationality is an instance). Such a complete theory would grant a higher status to rational humans, but it would still condemn our present treatment of non-human animals.

Plato, Aristotle, and Kant offer examples of moral theories in which rationality plays a central value-role. For Plato this value-role is mainly instrumental. Reason is that faculty which grasps quality in things--their measure, proportion, harmony, beauty.' Reason endows a being with value because reason can lead one to the highest level of reality--the realm of the forms. For Aristolle, rational activity--with its distinctive objects, its attendant pleasures, the ties of affection it enables-is itself the purest, most self-sufficient, most divine and ennobling of activities. ${ }^{2}$ in Plato's and Aristotle's eyes, to lack rationality is to be an impoverished, more limited, and less valuable being.

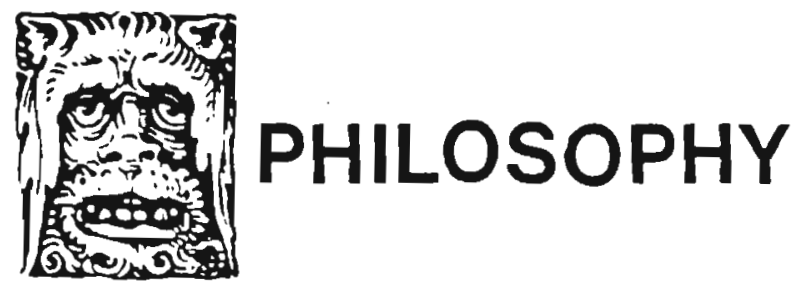


Those who lack some degree or more of the rational aspect, like non-human animals, natural slaves (and women, for Aristotle), must subordinate their ends to those of the fully rational humans.

Kant, and other fellow deontologists, also hold that what endows humans with value demanding of respect (dignity) is rationality. Rationality enables them to make free choices, to be autonomous centers of action, and thus to be not only different from, but superior to, lesser animals. It is this freedom which Kant asks us to respect when he exhorts us to act in such a way that one's principle of action admits of universalization, and thus of (hypothetical) approval by the recipients of one's action. If others would (upon rational consideration) approve of my principle of action, then in effect their wishes, will, freedom, are not being violated by my act. Since freedom, for Kant, derives from reason, a proper action is one which respects another's reason. A. Donagan expresses this point when he states:

Since treating a human being, in virtue of its rationality, as an end in itself, is the same as respecting it as a rational creature, Kant's formula of the fundamental principle may be reinstated in a form more like the scriptural commandment that is its original: Act always so that you respect every human being, vourself or another, as being a rational creature. ${ }^{3}$

The major philosophical alternative to rationality as the central value in a moral theory is pleasure (broadly construed to encompass all positive sentient states of consciousness). Bentham and Mill are among those who have considered pleasure as the only intrinsic value. To be sure, Mill tries to differentiate between lower- and higher-quality pleasures, with intellectual pleasures placed at the top of the quality scale. Given this addition, Mill can claim that rationality and autonomy are of particular instrumental value, because among other things they enable one to experience the highest pleasures in life. However, should all feeling be removed from the universe, rationality and autonomy would presumably be stripped of all value. Freedoms, books, and paintings that cannot be experienced and enjoyed become, on this view, worthless. I will say more on this later.

\section{**}

In addition to pleasure and rationality are there other plausible contenders for the role of ultimate, non-reducible values? The following come to mind: love (of others, of creation, of the Divine); the highest objects of love (the forms, the One, the Brahman, the Judeo-Christian God...); the soul or Atman; existence itself, in any form. Since this issue is not central to my present task, my comments on these other candidates for intrinsic value will be brief--perhaps too brief.

Love has often been sung by poets, prophets, and philosophers as the highest object of praise. However, what tends to be the case in their celebrations of love is a focus on the higher and purer forms of love (cf. Paul's famous characterization in Corinthians I, chapters 13-14). No one eulogizes love of cruelty, bestiality, or even common heterosexual love. Perhaps it is improper to characterize the feelings directed at such objects as love. Perhaps love surfaces only in connection with higher objects and with things of beauty (outer or inner). But if one's feeling for cruelty is intense and persistent enough, why not call it love? Should love not be identified phenomenologically and behaviorally (and not through its correlative objects)? If objects characteristically pleasant can give one pain (e.g., Beethoven's Ninth Symphony becomes painful to hear for Alex in Clockwork Orange), why cannot objects normally hateful evoke love? I propose that they can, and that to say otherwise is to beg the question. If so, love itself cannot be intrinsically valuable since some instances of love are objectionable.

However, perhaps traditional praise of love is directed at the feeling per se, independently of its objects. What is sought is perhaps an enriched intensity of feeling and life. If so, love may be advanced as intrinsically valuable. But then the position becomes a form of hedonism. Love as feeling would accrue intrinsic value insofar as the feeling is desirable. The hedonist can easily acknowledge the 'higher' forms of love, namely, 
those which have the further merit of promoting the happiness of others.

What about the highest objects of love: Divine Dojects or Divinities--do these have intrinsic worth? Again, only a few comments will be possible on this complex matter. First, some see 'divine' as implying perfection and ultimate value. Plato and Aristotle are amongst these; and supporters of many religions also fall in this group. Others, including some interpreters of Christianity and of other major religions, prefer to distinguish between benevolent and malevolent divinities. For these latter theorists, divinity itself is not a mark of value. What makes some Gods valuable, then, turns out to be some other quality like benevolence. If so, the valued quality may admit of some utilitarian-hedonistic analysis.

Those who find the divine reaim as excluding imperfaction and evil, are more difficult to deal with. This is particularly the case when mystical and 'negative' theologies are involved. Quite possibly the mystics have had access to a realm of perfection and of sul generis value. But if this realm and its value is indeed sul generis, and incomprehensible for us non-mystics, then the best we can do is plead ignorance and leave this optlon open. Often, however, those who identify the divine with perfection view the divine reaim as including perfected versions of human traits: thought, consclousness, will, pleasure, power. If the ordinary value of these traits can ultimately be attributed to the pleasures and satisfactions they provide (both intrinsically and instrumentally), then, again, it can be maintained that what makes the existence of divinities (or of our souls raised to divine levels) inherently and consequentially valuable is the pleasure-satisfaction they experience and enable the world to share in (to whatever degree). Something similar can be said if human powers derive their value from rationality. The Platonic Forms, for instance, as the ultimate rational objects, are made to order for a value-theory based on rationality

Might the hedonist say that the Forms' value derives from the activity of the minds (human or divine) which grasp and comprehend them? In comprehending them, perhaps minds experience their highest and most perfect satisfactions. Such satisfactlons after all do have ordinary counterparts. The artist who finally captures an elusive intelligible form (a "significant form" for Clive Bell) on canvas or through some other medium. experiences an intense satisfaction. An intellectual who finally sorts out, clarifies, and sets in order the threads of some particularly difficult and convoluted subject matter, also feels a distinctive satisfaction. Being able to carry out these expressive, ordering feats at higher levels must surely carry with it higher degrees of satisfaction. Whether the experiential (hence instrumental) aspect is all there is to the value of quality, order, beauty, form, the Forms, is a rich and complex question. I will say more on it later.

Christian tradition attributes intrinsic value to the soul, shared by all humans and making them equal in the eyes of God. Non-human animals, in contrast, elther lack a soul or possess a lower and mortal type of soul. Thus in Christianity there is no question of the resurrection and eternal life of non-human animals. The soul has been viewed as that immaterial substance in us in which perception, sensation, thought, judgment, and will are centered. The key problem with attempts to derive intrinsic value from souls is that such attempts merely tend to postpone the problem of value without solving it. Thus, one will want to know what makes the human soul particularly valuable. Is it its belng a soul? Is it its being a human soul? Is its having certain species-neutral attributes?

If the answer is that being a soul makes us valuable, we should want an explanation of this claim. What is it that makes souls valuable? One answer would appeal to the pewers of souls (and of human souls in particular). This would lead to cognition, rationality, and free will as the valueendowing attributes, since the powers of sensation and perception are shared by the other, less valuable, animals. But at this point we are back to Aristotle and Kant.

A second option would be to say that there is something divine and indefinable about souls from which value derives. However, to say that $X$ is valuable because there is something valuable in $X$ is to make no explanatory progress. I see no other options, so I conclude that the notion of soul does not 
add any new intrinsic values to the oneg thus far surmised.

On the Neo-Platonic and Augustinian view that all existence is good, i.e., endowed with intrinsic value, I will make only one comment. The only way this view has plausibility is on some panpsychistic view of matter. Otherwise, I fail to see how one justifies attributing any degree of intrinsic value to every speck of matter. If one does interpret the view panpsychistically, then one leaves the door open for some hedonistic analysis of the value attributed to every existent.

I conclude, albeit tentatively, that rationality (broadly construed to include the power and activity of thought, of reflective autonomous choice-making, of intellectual abstract comprehension, of artistic expression), and pleasure (broadly construed to include the satisfying, such as one feels upon carrying out and completing an intellectual or artistic exercise) emerge as the only candidates for intrinsic value. Can either alone be sufficient as the centerpiece of a complete and impartial moral theory? I belleve not, though for different reasons.

Consider first rationality-based theories. Clearly if rationality were the only value worth upholding, and if the power of abstract thinking (involving items like numbers, and principles) were required for rationalty, then clearly some humans and all non-human animals would lack intrinsic value. Surely, this consequent is false. Perhaps no actual rationality-based theory is this pure and exclusive. Thus, the target of this point may not be any major historical theory.

Yet Aristotle, Kant, and perhaps others, have come perilously close to advancing this extreme rationality-based view. Aristolle, after all, justified slavery on the grounds that some humans are less than rational. He argued on similar grounds for a subordinate role for women and children. ${ }^{4}$ And, clearly, a case can be made that on Aristotle's view non-human animals have no intrinsic worth.

Kant, too, on at least one occasion attributes a lower value-status to women, since he finds them incapable of acting from (rational) principles. ${ }^{5}$ And about animals he says the following:

Animals are not self-conscious and are there merely as a means to an end. That end is man...our duties to animals are merely indirect duties to mankind. ... If a man shoots his dog because the animal is no longer capable of service, he does not fail in his duty to the dog, for the dog cannot judge, but his action is inhuman and damages in himself that humanity which it is his duty to show towards mankind. ${ }^{\circ}$

Beings whose existence depends, not on our will, but on nature, have nonetheless, if they are non-rational only a relative value and are consequently called things. ${ }^{\text {? }}$

A. Donagan, while not addressing the issue of animals directly, says the following about other less-thanrational creatures:

The insane, who cannot wholly take care of themselves, must be looked after; and, if it is necessary for their well-being, may be constrained to do various things they would not do if they had their own way. The question of how far a man's insanity gives right of coercion is a difficult one.... The general principle, however, is clear: since a madman is a rational creature whose reason is impaired, he is entitled to the respect due to a normal rational creature except to the extent that the impairment of his reason makes it necessary to prevent harming himself or others.... ${ }^{8}$

Clearly, the implication is that non-human animals, insofar as they are not rational creatures, are not deserving of respect. Note also the insistence on calling the insane "rational creatures" despite their often permanent lack of rationality. This is a case of a Kantian unwilling to accept the implications of Kantianism.

It is, of course, possible to take Aristotelian or Kantian outlooks without unduly depriving various creatures of intrinsic value. This can certainly be 
done by admitting other intrinsic values in addition to rationality, but subordinate to it. In such a case, however, the theory would not be a pure rationalttybased theory. I will, in fact, argue for such a mixed theory later.

One can also moderate a rationality-based outlook by treating rationality as subject to degree. Even 50, however, those (would-be) sentient creatures devold of any rationality would still end up being intrinsically valueless. Such an outcome would be unacceptable. For, whatever the rational powers of a being. its feeling pleasure would be objectively preferable to its feeling pain (everything else being equal). Moreover, in addition to this philosophical objection, one must not forget the historical point that Aristotelian and Kantian outlooks have tended to inflate the value-gap between some/most humans and "lower" sentient beings. It is no accident that it was not Kant, but Mill who broke with tradition and argued not only for the equal status of women, but also for the recognition of the intrinsic value of animals. ${ }^{9}$

\section{***}

Consider now the opposite kind of moral theory-one which derives all value from pleasant states of consclousness. Let us call this theory Hedonistic Utilltarianism (HU). 10

HU has been commonly attacked on the grounds that it is at odds with our deeply held moral judgments concerning the value of individuals (particularly human individuals). From the viewpoint of common moraility, while HU is capable of endowing non-humans with intrinsic value, it necessarily underestimates the value of individual humans. This underestimation is due to the fact that $\mathrm{HU}$ conceives the individual as a value-neutral receptacle--a mere bearer of pleasant and unpleasant experiences."I These latter experiences alone are treated as intrinsically valuable or disvaluable. Consequently, on HU, the aim of morailty becomes the maximization of pleasant experiences, impersonally considered. This view, opponents claim, is flawed because it falls to take into account--hence fails to protect-the value, rights, sacredness, of the individual (human). For example, it is alleged that HU must in some cases recommend the sacrifice, in secret, of a healthy innocent person, if his/her organs can be used to save a number of other persons of similar age and potential. Since this is surely morally repulsive (it violates the individual's rights), $\mathrm{HU}$ in recommending this course of action, proves itself inadequate. In short, it is unequipped to capture and explain the immeasurable value of the individual (human) as recognized by our considered moral judgments

I grant that here there is a conflict between $\mathrm{HU}$ and our "considered" moral judgments. 12 When a similar conflict arose between our judgments and rationalty-based morality, we declared the latter as inadequate. Should we not do the same here, and declare HU inadequate? Note, however, that in the case of our considered attribution of intrinsic value to non-rational animals, we did find a rational basis for this, namely, sentience. Can we find a similar rational basis for our common attribution of immeasurable value to individuals (humans, particularly)? If not, perhaps we should, rationally, abandon this pre-theoretical moral judgment.

Is there something, then, about each individual human, other than sentience, which endows it with immeasurable intrinsic value? If vaiue does not derive from the contents of the receptable, it must lie in the receptacle itself. This is, after all, what is implied by the anti-utilitarians when they maintain that HU misplaces value in locating it among the contents of the receptacle. But how can the bare human receptacle/Individual/partlcular be endowed with special intrinsic value? If by "Individual" one means "bearer of properties" (or, similarly, "that which survives property-changes", or "that which individuates each member of a set of perfect clones"), then rocks would be, or would include, individuals. Yet, rocks are surely not sacred. Perhaps "individual", as used in moral contexts, means "bearer of sentience", or "bearer of human sentience", or even "bearer of rational sentience." Then, what we would want to know is in what sense is the individuality correlated with (human, rational) sentience superior to the individuality correlated with nonsentient properties? If it is not sentience, or rationality, or humanity, which supplies value, what can it be? How can the sheer individuality of 
the bearer of human properties do this? 13

At this point, one tempting option is to say that though we know, by intuition, that the human individual is endowed with a source of immeasurable value, we cannot explain what this is.

This is obviously a blind alley. Do we intultively recognize this $X$-value source only in some/all humans? Or also in other animals? In trees and flowers? In rocks? How do we know that this intuitive grasp is anything other than a speciespreserving blas resulting from evolutlonary pressures, and preserved through unclear thinking? I suggest that these questions cannot be answered satisfactorily.

A second option is to appeal to the soul as the value-generating aspect (other than sentience). But, as we have seen, to appeal to this notion is merely to postpone facing the problem. Are souls an exclusive possession of humans? Of human and some/all other animals? Of plants also? What differentiates soulpresence from soul-absence? Is it life? It is sentience? Is it rationality? What endows a soul with value? is it life, sentlence, rationality, or something else? In short, the notion of soul is a promisory note which needs to be cashed out. As soon as it is cashed out, it turns into familiar candidates of intrinsic value.

A third option is Kant's option: value accrues in individuals insofar as they possess reason. But this option has already proven itself hard to digest. Moreover, is rationality endowed with intrinsic value? A case can be made that its entire value is instrumental. I will return to this issue later.

For the present 1 conclude that though, as the critics observe, HU is unable to capture and explain at least one central judgment of common considered morality, this is insufflcient to prove the inadequacy of HU. What this clash appears to imply instead, is that deontological views of rights and absolute prohibitions, resting as they do on the absolute value of the individual human, might have to be abandoned. And this paves the way for the permissibility of harming innocents as a means to bring about some impersonally greater net good. I admit that this is troubling and repugnant, but I cannot justify my repugnance.

Perhaps why we find this repugnant is because, as T. Nagel argues, our viewpoint on the world is not confined to the impersonal, impartial, objective perspective. We also face the world from a subjective, personal, partial perspective. Thus, if I am a doctor who could secretly kill $A$ (say $A$ is an innocent old man who would die in a matter of months anyway, but who refuses my pleas for voluntary self-sacrifice) in order to save four promising young people, who would otherwise die, I might not be able to bring myself to kill $A$ in a personal face-to-face manner, no matter what the benefits. ${ }^{14}$ But if I were simply told that depending on which button I press, elther one or four Innocent Martians will die presently on Mars (pressing no button means the four will die), I might find it less difficult to save the four by killing the one. In the latter case I am able to adopt a more impersonal viewpoint than I could in the former case.

At any rate, this possible explanation for $m y$ unwillingness to harm innocents in order to produce a greater net good, does not rationally justlfy this unwillingness and repugnance, ${ }^{15}$ Thus the latter attitudes are not clear detectors of immorality. Consequently, they do not constitute a rational objection to HU. ${ }^{16}$

$$
\text { *** }
$$

It might be pointed out to us that while we are appalled at the idea of using some humans as means to some greater common good, we are not similarly struck by the massive use of other highly sentient species for our purposes. That is, such massive abuse is perpetrated on grounds even less acceptable than utilitarian grounds. At the very least a utliitarian outlook would require taking into account all sentient creatures. Our use of animals is generally directed at human good only.

Naturally, this point would be ad hominum. Afi impartial deontologist could defend the deontologically-based rights of individual humans, and also simultaneously extend rights-attribution to other sentient creatures. This is done, for example, by Tom Regan in The Case for Animal Rights. His attribution of rights is based on "the subject-of-alife criterion." 
To be a subject-of-a-life...involves more than merely being alive and more than merely being conscious. To be the subjectof-a-life is to be an individual whose life is characterized by ... [having] beliefs and desires; perception, memory, and a sense of the future, including their own future; an emotional life together with feelings of pleasure and pain; preference and welfareinterests; the ability to initiate action in pursuit of their desires and goals; a psychological identity over time; and an individual welfare in the sense that their experiential life fares well or ill for them, logically independently of their utility for others and logically independently of their being the object of anyone's interests. Those who satisfy the subject-of-a-life criterion themselves have a distinctive kind of value--inherent value--and are not to be viewed or treated as mere receptacles lof intrinsic value (which Regan attributes to pleasant experiences)]. ${ }^{17}$

Regan holds that to have "inherent value" is a sufficient condition for having rights. Moreover, "Inherent value" is of a kind incommensurate with intrinsic value (i.e., value based on pleasant experiences). And since many non-human animals according to Regan do satisfy the above requirements, they will have such "inherent value.' Thus, many non-human animals should also be recognized as having non-utilitarian rights. Witness, then, a species-neutral kind of deontological view.

The soundness of this view rests, however, on the plausibllity of placing a special kind of value-"inherent value"--on, roughly, being a self (a "subject-of-a-life"). The claim is that this kind of value is independent of the intrinsic value of some types of experiences. It is the kind of irreducible and non-instrumental value which endows one, as an individual or receptacle, with one's own distinctive worth. It is what makes some individuals sacred, and what precludes their use as means only.

But is the distinction between having "inherent" value (i.e., value as an individual and having "intrinsic" value (i.e., value derived from conscious experiences) tenable? I believe not.

It is clear that Regan operates according to a substance-attribute metaphysics. He does not want to derive value from the attributive-pole, for this would lead to an impersonal ethics. Thus, he is left with the substance-pole as the source of intrinsic value. However, as we have already seen, in the most general sense of "substance" / individual" -namely, as "bearer of properties," etc.--no substance/individual can be, aua substance/individual, any more or less valuable than any other. Clearly, then, it must be in some other narrower sense of "substance"/ "Indivldual" that Regan believes special value accrues to some individuals. This other, narrower, sense of "individual" is what can be called "self" (or "subject-of-a-life"), But what differentiates selves-individuals from nonselves-individuals? I suggest that only some attribute, or set of attributes, can do so. Given the substance-attribute assumption, there is no other choice.

And, in fact, as we have seen, Regan makes use of a definite set of traits to explain what endows any $X$ with the status of self. This set of traits includes consclousness, feeling, desires, belief, perception, self-consciousness, memory, having a sense of the future, having a psychological identily over time, and having the ability to initiate goal-directed action. For Regan, being a self is having these traits. It is not some additional aspect emerging from the union of these traits.

Thus, Regan's distinction between "inherent" and "intrinsic" value is really an attribute-based distinction; it is not a distinction having individuals on one side and attributes on the other. "Inherent" value is simply a kind of "intrinsic" value. The latter derives from the attribute of sentlence (feeling, consclousness, desire, etc.); the former derives from a combination of attributes: sentience plus cognition-rationality-autonomy (beliefs, desires, perception, memory, having a sense of the future, having a psychological identity over time, initiating goal-directed action). Thus, Regan does not really transcend the traditional rationality/sentience dichotomy. His contribution is the claim that combining sentience and rationality yields a value which is higher than, and which differs in kind from, 
that of sentience alone.

The assumption behind this last claim is, I take it, that a disconnected sequence of states of consclousness (even when such states are singly of intrinsic value) does not carry as much, or the same kind of, value as does a stream of consciousness which is internally unifled, self-cognizant, goaldirected. The latter features can be seen as the 'form' for which sentient states are the 'matter.' To have both is to be a self (in Regan's or Kant's sense) --as opposed to being a "Humean" mind. Only once one is a self does one, for Regan, acquire special value as an individual.

The thesis that a broad form of rationality enhances the value of sentience (perhaps because it enables enriched forms of experience) has some plausibility. Even HU may accept it. It can thus be argued that a being who has both sentience and rationality is of higher value than one who has only sentlence (we will come back to this). However, from this it does not follow that the increased value is immeasurable; or that it is incommensurate with "Intrinsic" value. Once one sees the attribute-type basis of both values, such extravagant claims lose their initial attractiveness.

If it did follow that "inherent" value is uniquely immeasurable, it could be used to do exactly the opposite of what Regan wants it to do. It could be used to defend a Kantian type of speciesism. For it is highly unlikely that non-human animals possess the cognitive-rational powers necessary for traits like the genuine possession of "a sense of the future, "or of self-consciousness, or of "a psychological identity over time." Each of these traits requires the ability to abstract from the here-now; and this in turn requires being equipped with conceptuallinguistic powers (Kant's "categories" and "Forms of intuition" ) which are beyond the reach of most/all non-human animals. ${ }^{18}$ Thus, Regan's ploy--his intrinsic/inherent distinction--even if granted would fail to establish value and rights parity between humans and other species of animals. If granted, it would not exempt the latter from being legitimately used by humans as means only.

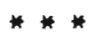

What has been shown thus far? (1) We have seen that HU does violate some important orima facie moral judgments; (2) these judgments, however, are based on the attribution of a special kind of value to (human) individuals; (3) attributions of this special kind of value have been found to be suspect: (4) therefore, HU's violation of these prima facie moral Judgments do not prove the inadequacy of $\mathrm{HU}$.

Before HU can be embraced, hawever, we must consider an important datum noted by Regan, Kant, Plato, Aristotle, ... and by J.S. Mill. The datum is rationality's capacity to enhance the value of mere sentlence. That this is so is shown by the fact that if there were a soma-pill which would guarantee us a future consisting of a succession of pleasant, conscious states--but a succession lacking form, unity, self-control--most/all of us would recoil from taking the pill. We would prefer to be "subjects-of-a-life," autonomous agents, rational beings, even at the cost of a good deal of hardship and suffering. Does this datum reinstate the higher value of most humans? And how does $\mathrm{HU}$ account for it?

This datum can be explained in two ways. Either rationality is an intrinsically valuable element, or it is an instrument useful in generating richer forms of pleasure/satisfaction. The latter option is chosen by Mill. The others have chosen the former option.

What counts for Mill are the richer, higherquality, pleasures "of the intellect, of the feelings and imagination, and of the moral sentiments." 19 These pleasures render the possession of rationality a particularly valuable asset. Being of higher quality, they outwelgh much larger quantitles or lower pleasures. Proof of this is our refusal to take the hypothesized soma-pilis.

Naturally, this latter refusal does not prove that the higher value of the rational-sentient life derives from higher-quality pleasures. Opponents would maintain that this value derives from rationallty, autonomy, and from a connected sense of dignlty. How does one decide whence the value derives?

Consider a small-scale version of this problem. Consider the intellectual activity of solving a math 
problem (or arriving at a brilliant chess move, or finding the right words to complete a poem or to summarize an argument). These activities are surely attended by a distinctive feeling of satisfaction or even elation. We would not trade these rational activities for activities (or passive states) accompanied by more "primitive" pleasures. Is that because of the rational nature of the former, or because of the distinctive pleasures attending them? Aristotle in his famous discussion of this in his Nicomachean Ethics, Book $X$, opted for the former. In so doing he relegated the role of pleasure to that of "completing" the activity. But the obvious question Aristotle must face is whether such rational activities would still be of value if stripped of the pleasures attending them. One would think not. After all, computers can perform these activities without such activities thereby accruing any intrinsic value.

Perhaps this is so only because computers are mechanical rational agents, and not autonomous rational agents. Hence their activities, albeft rational, lack value.

However, even after adding this element of autonomy to computers, so that their behavior becomes both rational and unpredictable and whatever else is needed to make it autonomous, I would imagine that the resulting super-computer and its activities would still not have intrinsic value, unless conscious sentience were to be added. Would this non-sentient autonomous computer be susceptible to harm and benefit? Again, one would think not, though it could be damaged. If this is so, Kant's ground for respect--the autonomy/rationality of a being--is undercut. HU seems to have won the day.

But, somehow, there is something unappealing in the view that my life is preferable to that of a happy pig simply because it makes possible higher-quality pleasures. Is our sense of dignity and self-esteem not based on something else? And is the bioher quality of our pleasures/satisfactions not based on some non-hedonístic value (like autonomy)?

The latter has been a traditional objection to Mill's version of utilitarianism. Mill's position is that what endows some pleasures with higher value than others is the same factor that endows any pleasure with value--namely, the primitive experlentlal fact that we like to feel pleasure. We like to feel some pleasures more than others. Those who know both prefer intellectual-artistic pleasures to the (often) more intense pleasure of the flesh. Thus, the former are of higher quality. Such higher quality has, therefore, a hedonistic foundation. That is the end of the story for Mill.

But is preferring $X$ to $Y$ the same as liking to feel $X$ more than $Y$ ? Is there anything we like to feel more than food, drink, and sex? Admittedly, if forced to choose, those who have also experienced intellectual-artistic pleasures might prefer a life containing only the latter pleasures to a llfe containing only the more intense pleasures of the flesh. But is this simply due to our liking some feelings mere than others? Might not our preference be based on other factors?

Naturally, such other factors may be simply the greater safety, stability, self-sufficiency of the intellectual-artistic pleasures. But these are not ennobling factors--they are merely prudential ones. That is, I suspect, why Mill himself rejected the use of these factors in explaining the hlgher quality of some pleasures.

Clearly Mill, too, like Plato, Aristotle, and Kant, wants to capture that special quality which endows some human activities with (the potentlal for) dignity and nobility. But it is not clear that he succeeds in this through purely hedonistic terms.

As an alternative, I suggest that our world has certain objective, non-experiential features which somehow have independent worth. Such features seem to have an irreducibly formal aspect. The orderliness, symmetry, organization,....in such disparate things as butterflies, sunsets, numbers, natural cycles, musical patterns,... and human rationality, have long been viewed by thinkers and poets as endowed with a special significance (l.e., beauty?) not derived from the experience of subjects. No one more than Plato appreciated this formal, aesthetic, qualitative aspect of our world. Following the Pythagoreans, he tended to explain this aspect in terms of the harmony of parts. Physical 
beauty, moral goodness, social justice, cosmic grace, for Plato, derived their attractive quality from the harmonious arrangement and operation of constituents. Reason he saw as that faculty which seeks, identifies, and appreciates proper form, or beauty. In some sense, rationality (broadly construed) is both a mirror to the beauty of the world, and an example of this formal aspect of order. Thus, we see reason's natural disposition towards well-rounded creations. As an example of this pervasive aspect of harmony, symmetry, form, reason too shares in the peculiar value of this universal aspect. It is this aspect which eludes (nonhuman) animal consciousness.

But how can form, symmetry, have intrinsic value? Would a world of beautiful things with no conscious subjects to experience them be any more valuable than a thoroughly ugly world? I would think not.

Yet, it is as if the value of a beautiful but subjectiess world were there in potential, dormant form, as if hidden by darkness. Then the light of consciousness comes, and its value is unveiled, discovered, but not created.

Some might object that the symmetry of colors, shades, numbers, words...--the beauty we detect-derives its value from our specific perceptualpsychological make-up. A rational being with the perceptual apparatus of a bat would fail to detect the 'beauty' of a piece of music.

Yet the pattern of notes underlying the music, for example, could be appreciated visually and mathematically (e.g., by transiating it into some clever color pattern, or graph pattern, or numerical pattern). Thus, we might reply that beauty has a dimension which transcends any one perceptual mode, though not necessarily all perceptual modes. Beauty is built on a foundation of symmetry and regularity which can be abstracted from a specific medium. Such a foundation has a rational make-up, and that explains why rationality can detect it.

It may well be that rationality has no intrinsic value--since it needs to be triggered into valuestatus by sentient consciousness. But once triggered, it adds to the world a value independent of pleasure. This appears paradoxical. But is it any more paradoxical than saying that a seed, in containing the genetic blueprint of a tree, in a sense is already a tree, though it needs the matter to fill out the genetic form? indeed the tree would not exist without the matter; but a tree is no mere chunk of matter. Likewise, the blueprint contained in the seed of rationality adds an essential element to the matter of sentience.

This solution, if tenable, would explain why thinkers from Plato to the present have viewed rationality as the source of the greatest (or of all) value. It would also explain Mill's version of a utilitarianism which tends to overnow its hedonistic boundaries. And it may, finally, explain our higher status when compared with non-rational sentient creatures. This higher value does not, however, put us on some infinitely higher pedestal. Hence, it does not justify using non-rational creatures as means to satisfy our wants, for they, if sentient, have intrinsic worth as well (on a par with mentally disabled humans). Perhaps in extreme survival situations, where we must choose between elther some of us or some non-rational sentient beings, it might be justified to destroy some of the latter (painlessly, if possible). But this is not, generally speaking, our situation today. There are plenty of other options available in dealing with problems of resources, of animal growth-containment, etc. Thus, our present treatment of millions of sentient creatures remains unjustifiable.

\section{ENDNOTES}

1. E.g., Plato, Philebus 66.

2. Aristotle, Nicomachean Ethics, Book $X$, Chapters 6-8.

3. Alan Donagan, The Theory of Morality (Chicago: The University of Chicago Press, 1977), p. 65 .

4. Aristotle, Politics, 1, 13, 1260a 10-15; see also on the Generation of Animals IV , 6, 775a 15.

5. "The virtue of the female sex is a beautiful virtue. That of the male must be a noble one. Those 
avoid the bad, not because it is wrong, but because It is ugly, and virtuous actions signify, with them, such as are morally beautiful. Nothing of ought, nothing of must, nothing of due. All orders and all surly compuision are to women insupportable. They do something but because they are pleased so to do, and the art consists but in making that which is good pleasing to them. I hardly believe that the fair sex are capable of principles..." I. Kant, Observations on the Feeling of the Beautiful and Sublime, section 3 , included in Women in Western Thought, ed. Martha Lee Osborne (New York: Random House, 1979), pp. 156-7. I owe being made aware of this passage by Kant to Thomas Lapic. He points out in an unpublished manuscript that since women, for Kant, act only from inclination and not from principle, they are not moral and are not "embodiments of the law" or "laws unto themselves," Since the basis for value and respect is the moral law, and women do not embody this law, it follows that women are not deserving of respect (are of lesser value), on Kant's theory.

6. Immanuel Kant, "Dutles to Animals and Spirits," in Lectures on Ethics, Trans. Louis Infield (New York: Harper and Row, 1963), pp. 239-241.

7. $\longrightarrow$ Groundwork of the Metaphysic of Morals (New York: Harper and Row, 1964), p. 96.

\section{A. Donagan, The Theery of Morality p. 82.}

9. Consider, for example, this exchange between J.S. Mill and William Whewell on the relative value of human and animal pleasures:

Whewell: "The pleasures of animals are elements of very different order from the pleasures of man. We are bound to endeavor to augment the pleasures of man, not only because they are pleasures, but because they are human pleasures. We are bound to men by the universal tie of humanity, of human brotherhood. We have no such tie to animals. ... It is not only not an obvious, but to most persons not a tolerable doctrine, that we may sacrifice the happiness of men provided we can in that way produce an overplus of pleasure to cats, dogs, and hogs." Lectures on the History of Moral Philesoohy in England (London: Parker, 1852), pp. 223-5.

Mill: "It is 'to most persons' in the Slave States of America not a tolerable doctrine that we may sacrifice any portion of the happiness of white men for the sake of a greater amount of happiness to black men. It would have been intolerable five centuries ago 'to most persons' among the feudal nobility, to hear it asserted that the greatest pleasure or pain of a hundred serfs ought not to give way to the smallest of a nobleman. According to the standard of Dr. Whewell, the slavemasters and the nobles were right. They too felt themselves 'bound" by a 'tie of brotherhood' to the white men and to the nobility, and felt no such tie to the negroes and serfs. And if a feeling on moral subjects is right because it is natural, their feeling was justifiable. Nothing is more natural to human beings, nor, up to a certain point in cultivation, more universal, than to estimate the pleasure and pains of others as deserving of regard exactly in proportion to their likeness to ourselves." "Whewell on Moral Philosophy" in Essays on Ethics. Religion and Society (Canada: University of Toronto Press, 1969), pp. 185-6.

10. I say Hedonistic Utilitarianism, instead of Hedonistic Egolsm, because, with T. Nagel, I find that if value lies in pleasant experiences, it does so for all pleasant experiences, irrespective of their bearer (self or others). Cf. Thomas Nagel, Ihe View from Nowhere (New York and Oxford: Oxford University Press, 1986), pp. 160-1.

11. For a version of this objection, see $T$. Regan, The Case for Animal Rights, pp. 205-6.

12. Attempts to reconcile the two through appeals to rule-utilitarianism are, in my view, unsuccessful. 
For example, rules which allow for utilitymaximizing exceptions would have to be preferred to rules that do not.

13. I come back to this point later, in the course of discussing $T$. Regan's view.

14. Note that there are many things which because of personal bonds I cannot bring myself to do, even though morally I should. Examples: (1) I may be unwilling to turn my son in to the police even though I know he has committed a serious crime; (2) I may be unwilling to send my daughter to a relatively inexpensive state college when I can afford to send her to a more reputable and expensive Ivy League college, even though the savings accrued from the former cholce can fund the state college education of five additional poor but promising students (without significantly depriving my daughter of learning opportunities).

15. Nagel, I think, denies this, but his argument is less than convincing. For his fascinating discussion, see pp. 172-204 in The View fram Nowhere.

16. A second and related moral judgment which HU allegedly falls to capture and explain concerns distributive justice. We think that any morally correct distribution of benefits and burdens has to be a fair distribution. HU, on the other hand, in its focus on impersonal pleasant experiences, is equipped to justlfy only that distribution which yields the greatest net total of such experiences, irrespective of distributive fairness. Thus, if it turned out that the greatest net total of pleasant experiences in a society can in the long run be achleved by having a mlnority-group (or another species) employed as slaves or as a permanent underclass, then this is the way society should be arranged, according to HU. This, again, being morally unacceptable (or is it? Witness our use of other species), HU must be inadequate.

One way for HU to respond would be to maintain that the above type of maximal, but unfair, distribution can in fact never occur, because there will always be other distributive options involving no disproportionate suffering by some subgroup which will produce a greater net total of good. This is difficult to assess, given various measurability problems in identifying and comparing pains and pleasures, satisfactions and dissatisfactions (and given also the issue of diminishing returns, et cetera).

But what if it did turn out that the maximal net good could be accomplished by the suppression of some? What if the sacrifice of one of us (chosen either candomly or on the basis of one's lack of instrumental value) would produce the cure for AIDS or cancer? Should we not all agree to carry it out? What if ten people would have to be sacrificed? Should we not still do it? What if the sacrifice of thousands (or mllitons) of cows and pigs yields the maximal net good for all sentient species? Should we not still do it? Once we grant that there is no rational basis behind the view that the (human) Individual is of immeasurable value, what prevents such disproportionate distributions from being morally permlssible (or even obllgatory)? Perhaps, again, HU might have to bile the bullet and grant its inconsistency with our moral Judgments about distributive justice, without thereby admitting any inadequacy.

17. T. Regan, The Case for Animal Riahts, o. 243.

18. T. Regan argues that some animals do have such capacities, but I find his arguments surprisingly hasty and meager. See The Case for Animal Rights, pp. $71-75$.

19. J.S. Mill, Utilitarianism.

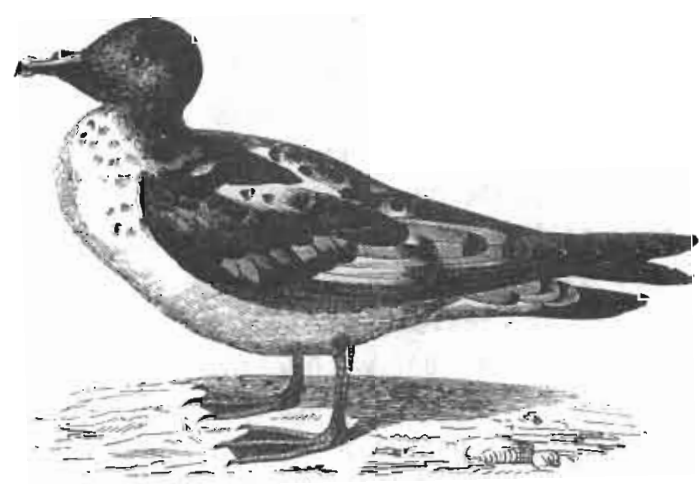

